\title{
Separação de Carotenóides, Clorofilas e Flavonóides EM Folhas de PlantAS: UMA ABORDAGEM SIMPLES E ECOLÓGICA
}

\author{
Alice M. Dias*, M. La Salete Ferreira \\ Departamento de Química, Universidade do Minho, Braga \\ ad@quimica.uminho.pt
}

\begin{abstract}
Separation of Carotenoids, Chlorophylls and Flavonoids from Plant Leaves: a simple and ecological approach - The experimental activity presented here aims to replace or supplement the traditional separation of chloroplast pigments by column chromatography, from green leaves. The new approach, using red and green leaves, leads to higher visual impact and involves simpler and greener procedures. To achieve these goals, a simple and ecofriendly procedure was developed to prepare extracts from these leaves. The chromatographic separation of this extract in a disposable syringe containing potato starch as adsorbent allowed an excellent separation of bands with yellow, blue-green, yellow-green and red colors, which were attributed to $\beta$-carotene, xanthophylls, chlorophylls $a$ and $b$ and anthocyanins, respectively. This activity can be useful in higher education in practical classes designed to teach chemistry laboratory techniques and fundamentals of organic chemistry. The challenges associated with the additional separation of anthocyanins, hydrophilic pigments, will broaden the learning outcomes of traditional activity, which separate only lipophilic pigments, and enable teachers to adopt targeted pedagogies to exercise critical thinking of the student. This activity is also suitable to primary and secondary education to stimulate young people to the chemistry and to demonstrate basic concepts of chemistry.
\end{abstract}

Descreve-se uma atividade experimental que pretende substituir ou complementar a tradicional separação dos pigmentos dos cloroplastos por cromatografia em coluna, realizada a partir de folhas verdes. A nova abordagem, usando folhas verdes e vermelhas, conduz a maior impacto visual e envolve procedimentos mais simples e mais concordantes com os princípios da química verde. Para atingir esses objetivos, foi desenvolvido um procedimento simples e ecológico para a preparação dos extratos destas folhas. A separação cromatográfica deste extrato numa seringa descartável contendo fécula de batata como adsorvente permitiu uma excelente separação de bandas coradas de amarelo, azul-verde, amarelo-verde e vermelho, que foram atribuídas aos pigmentos $\beta$-caroteno, xantofilas, clorofilas $a$ e $b$ e antocianinas, respetivamente. Esta atividade pode ser útil no Ensino Superior em aulas práticas vocacionadas para ensinar Técnicas Laboratoriais de Química e Fundamentos de Química Orgânica. Os desafios associados à separação adicional de antocianinas, por serem pigmentos hidrofílicos, vão alargar os resultados de aprendizagem da atividade tradicional, que separa unicamente pigmentos lipofílicos, e permitir aos professores adotar pedagogias direcionadas para o exercício do pensamento crítico do aluno. Esta atividade é também adequada ao ensino básico e secundário para despertar os jovens para a química e demonstrar conceitos básicos de química.

\section{INTRODUÇÃO}

Em Química, os métodos de ensino que assentam na experimentação são, cada vez mais, a chave para o sucesso no processo ensino/aprendizagem, em particular nas camadas mais jovens. A aproximação da química ao mundo real é um contributo importante para despertar e motivar os alunos para esta área do conhecimento. Por outro lado, sendo a química uma ciência crucial para a explicação de todos os fenómenos do meio físico e biológico é necessário inverter a imagem atual da química, normalmente associada a imagens de poluição e desastres ambientais, grandemente responsável pela aversão que os alunos e o público em geral desenvolveram atualmente pela química. Assim, a elaboração de experiências simples, com impacto visual e em que os materiais utilizados, para além de acessíveis e de baixa toxicidade, sejam produtos da natureza é um tema cada vez mais atual [1,2].

Neste sentido, os pigmentos das plantas são modelos privilegiados pelas cores com que ornamentam o mundo em que vivemos, pelas funções biológicas essenciais à vida, pelo papel fundamental na alimentação e pelos benefícios para a saúde [3,4]. Os pigmentos mais abundantes das folhas das plantas são as clorofilas (verdes), os carotenóides (amarelos) e os flavonóides, de entre os quais se destacam as antocianinas (vermelhos). As clorofilas e os carotenóides ocorrem nos cloroplastos onde desempenham funções essenciais na fotossíntese. As folhas de certas plantas também têm conteúdos significativos de antocianinas, conferindo-lhes lindas tonalidades de vermelho/roxo. As cores das folhas podem variar de acordo com a estação, nutrientes, pH e interações químicas [4].

A separação dos pigmentos vegetais clorofilas e carotenóides presentes em folhas verdes através de técnicas cromatográficas é um trabalho prático tradicionalmente encontrado nos manuais de Química Orgânica Experimental [5]. Trata-se de um trabalho experimental transversal à química e à biologia e que se caracteriza por um elevado impacto visual captando o agrado da maioria dos alunos. Os proce- 
dimentos experimentais descritos exigem laboratórios com equipamentos especiais e materiais perigosos que restringem a sua realização ao ensino universitário.

Tendo em vista a extensão deste trabalho ao ensino básico e secundário desenvolveu-se uma técnica simples e ecológica capaz de separar, não só os amarelos dos carotenóides e os verdes das clorofilas, mas também os vermelhos dos flavonóides, partindo de folhas verdes e vermelhas. Seguindo as linhas orientadoras da Química Verde [6], foram realizados vários estudos em que se investigaram vários adsorventes não tóxicos do quotidiano e solventes menos perigosos e de fácil acesso. Os problemas encontrados foram contornados recorrendo sempre a procedimentos experimentais simples, de modo a evitar técnicas e equipamentos tipicamente laboratoriais. Os resultados obtidos permitiram desenvolver técnicas de cromatografia em coluna e em papel muito simples e eficazes na separação das bandas coloridas típicas destes pigmentos que obedecem estritamente aos requisitos estabelecidos [7].

\section{DescriçÃo Global dA EXPERIÊNCIA}

A separação dos pigmentos das folhas dos espinafres por cromatografia em coluna tem sido a atividade laboratorial mais utilizada para demonstrar os fundamentos da cromatografia. Esta atividade normalmente decorre em duas etapas. A primeira etapa envolve a trituração das folhas e maceração num solvente de polaridade intermédia, seguida de extração líquido-líquido e evaporação da fase orgânica sob vácuo usando um evaporador rotativo. Na segunda etapa faz-se a separação do extrato em colunas de fase estacionária sólida, cujos adsorventes geralmente são sílica ou alumina, e a fase móvel é uma série de solventes orgânicas de polaridade crescente (série eluotrópica). A base da técnica e os princípios da adsorção e partição demonstrados são um bom suporte para a compreensão das técnicas cromatográficas mais avançadas, como a cromatografia gasosa (GC) e a cromatografia líquida de alta eficiência (HPLC), que são hoje ferramentas essenciais em qualquer laboratório de Química Analítica. O lugar de destaque desta experiência didática deve-se à acessibilidade da amostra e aos resultados obtidos, uma vez que a separação dos pigmentos pre- sentes em folhas de plantas é facilmente visualizada pelo deslocamento de bandas amarelas (clorofilas e xantofilas) e verdes (clorofila $a$ e clorofila $b$ ) de cor e/ou posição relativa diferentes. Esta atividade serve ainda para demonstrar os princípios básicos da química, particularmente da química orgânica, pois revela as características de polaridade e solubilidade das moléculas destes pigmentos, permitindo uma associação destas propriedades com os conceitos de grupo funcional, eletronegatividade, momento dipolar e interações intermoleculares.

As moléculas de pigmentos mais amplamente distribuídas em folhas de plantas são o $\beta$-caroteno, a luteína, as clorofilas $a$ e a $b$ e o glucósido de 3-O-cianidina [4]. As estruturas correspondentes estão representadas na Figura 1.

O $\beta$-caroteno e a luteína são pigmentos representativos da classe dos carotenóides [3,4]. Esta classe de moléculas, que inclui os carotenos e xantofilas, possui em comum um esqueleto carbonado composto por várias unidades de isopreno apresentando, por isso, propriedades lipofílicas. Os carotenos, sendo exclusivamente formados por átomos de carbono e hidrogénio, são moléculas apolares. As xantofilas, aqui representadas pela luteína, são ligeiramente mais polares devido à presença de um pequeno número de grupos funcionais oxigenados que, neste caso, são grupos hidroxilo. As clorofilas também são moléculas lipossolúveis devido ao predomínio de átomos de carbono e hidrogénio, em particular na longa cadeia hidrocarbonada do grupo fitilo. No entanto, o núcleo central de porfirina contém quatro átomos de nitrogénio nos anéis de pirrole e estes encontram-se coordenados com o metal magnésio. Este centro polar e os grupos éster e cetona presentes tornam as clorofilas mais polares do que os carotenóides e, por isso, normalmente requerem solventes de maior polaridade. A clorofila $b$ é ligeiramente mais polar do que a clorofila $a$ devido à substituição de um grupo metilo por um grupo aldeído.

Os flavonóides, pigmentos polares geralmente presentes em flores e frutas, também podem ser encontrados nas folhas de plantas, em particular em folhas vermelhas e verdes ou só vermelhas. Os componentes principais dos fla-

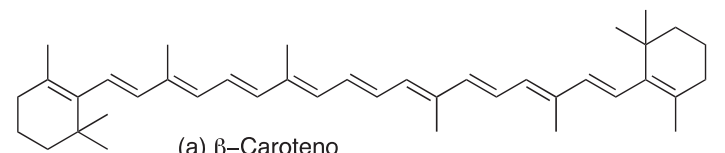

(a) $\beta$-Caroteno<smiles>CCCCCCCCCC(C)=CC=CC=C(C)C=CC1C(C)=CC(O)CC1(C)C</smiles>

(b) Luteína (xantofila)
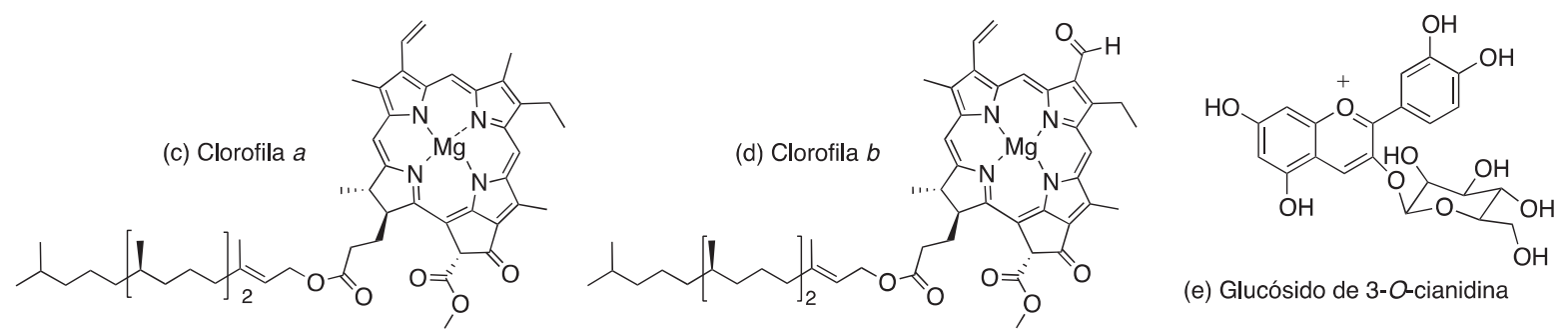

(e) Glucósido de 3-O-cianidina

Figura 1 - Moléculas representativas dos pigmentos presentes em folhas vermelhas e verdes: $\beta$-caroteno e luteína (carotenóides); clorofilas $a$ e $b$ (clorofilas); glucósido de 3-O-cianidina (antocianinas). Adaptado com permissão de J. Chem. Educ. 92 (2015) 189-192. (Copyright 2015 American Chemical Society) 


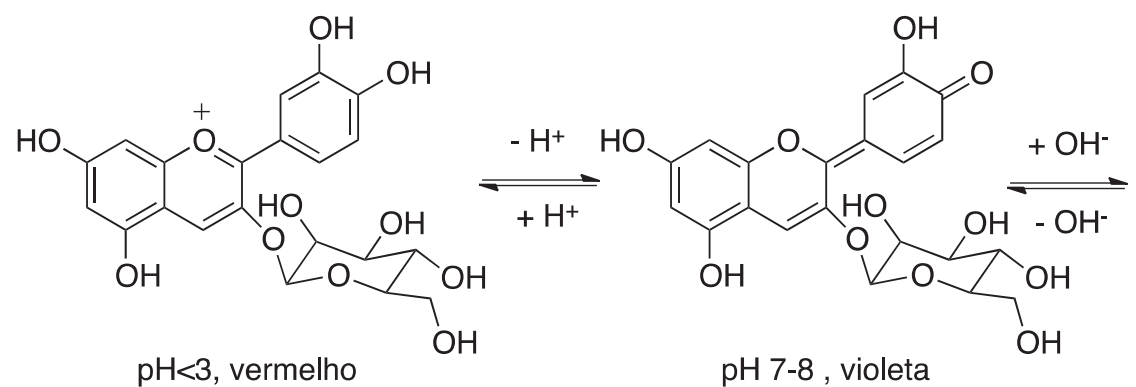<smiles>O=C1C=CC2=C3Oc4cc(O)cc(O)c4C=C3OC(OC3C(O)C(O)C(O)C(O)C3O)C(=C2)C1=O</smiles>

Figura 2 - Variação de cor do glucósido de 3-O-cianidina (antocianina) em função do pH. Adaptado de [4]

vonóides presentes nas folhas são as antocianinas, que são responsáveis pelas cores vermelhas observadas. A cor das antocianinas é dependente do $\mathrm{pH}$ do meio, sendo vermelha em soluções ácidas, roxa em soluções neutras e azul em meio básico (Figura 2) [4].

O glucósido de 3-O-cianidina (Figura 1e) é a antocianina mais frequente nas folhas. Nestes pigmentos, um núcleo de benzopirano está ligado a um anel polifenólico, a uma unidade de glucose e a grupos hidroxilo. Assim, é de salientar a elevada polaridade destes pigmentos devida ao caráter iónico e à presença de um elevado número de grupos hidroxilo, o que os torna solúveis em água.

Uma vez reconhecido o interesse na extensão ao ensino básico e secundário da separação dos pigmentos das folhas de plantas por cromatografia em coluna, face às suas potencialidades didáticas, impacto visual e aproximação à natureza, procurou-se na literatura um método que reunisse os requisitos experimentais e técnicos adequados a estes níveis de ensino. Foram encontrados vários métodos que utilizam adsorventes do quotidiano [8-14]. Destacou-se um método, reportado por Kimbrough [14], que reunia a simplicidade e acessibilidade pretendidas e explorava a separação em coluna de bicarbonato de sódio de um extrato obtido por maceração de folhas verdes e vermelhas em acetona. A experimentação deste método revelou que permitia o isolamento dos flavonóides, mas não separava os pigmentos amarelos e verdes dos cloroplastos. Para além disso, a coluna apresentava um impacto visual muito reduzido, uma vez que para além da banda verde brilhante correspondente à mistura de pigmentos amarelos e verdes dos cloroplastos, apenas se visualizavam os flavonóides como bandas castanhas e cinzentas devido à basicidade do adsorvente. Estabeleceu-se então como meta desenvolver um método capaz de separar na coluna as bandas amarelas, verdes e vermelhas correspondentes aos principais pigmentos presentes em folhas verdes e vermelhas, mantendo a simplicidade e sustentabilidade do método original.

A meta foi atingida pois, após um estudo sistemático, conseguiu-se separar numa coluna de fécula de batata duas bandas amarelas distintas correspondentes ao $\beta$-caroteno e às xantofilas, uma banda verde azulada correspondente à clorofila $a$, uma banda verde amarelada da clorofila $b$ e uma banda rosada das antocianinas [7]. Estes resultados podem ser obtidos através de uma experiência muito simples, no período de 2-3 h sem recorrer a técnicas e/ ou equipamentos sofisticados e sem expor os pigmentos a condições de degradação. A simplicidade e originalidade do método reside na preparação de um extrato sólido que envolve a adsorção dos pigmentos lipofílicos e hidrofílicos na superfície dos pequenos grânulos da fécula de batata.

A utilidade deste extrato também otimizou o método de Kimbrough em colunas de bicarbonato de sódio, mas os resultados são muito inferiores aos obtidos com fécula de batata. Também foram testadas sem sucesso colunas de amido de milho e açúcar em pó. Os resultados demonstraram que os grânulos do amido de batata apresentam características físicas e químicas mais adequadas a esta atividade do que os grânulos do amido de milho.

A utilização do amido de batata nesta atividade constitui uma abordagem original e que apresenta vantagens sobre os adsorventes usuais. Para além da sua elevada sustentabilidade, a separação é muito mais eficiente e, sendo um material quimicamente inerte, não há degradação dos pigmentos nem alteração da cor das antocianinas.

\section{Procedimentos Experimentals}

\section{Preparação e Análise do Extrato}

Folhas frescas de Stromanthe sanguinea (Figura 3a) (6 g) foram cortadas com uma tesoura e esmagadas usando um almofariz e um pilão. Os pigmentos das folhas foram extraídos por maceração em acetona (15 mL) durante 15 minutos. O extrato bruto, obtido por filtração, foi tratado com um agente exsicante (sal de cozinha ou sal sulfato de sódio anidro, 15 min, Figura 3b). Após a eliminação do sal por filtração, adicionou-se fécula de batata comercial (1 g) a uma porção da solução filtrada $(0,5 \mathrm{~mL})$ e toda a acetona evaporou ao fim de 5-10 min para formar um extracto sólido (Figura 3c), pronto para ser aplicado diretamente sobre uma coluna de fécula de batata. A composição do extrato líquido (b) foi avaliada por cromatografia em papel, usando uma mistura de éter de petróleo 40-60 ${ }^{\circ} \mathrm{C} /$ acetona (9:1) como fase móvel. Os pigmentos foram identificados através das suas cores e polaridades características (Figura 3d). 

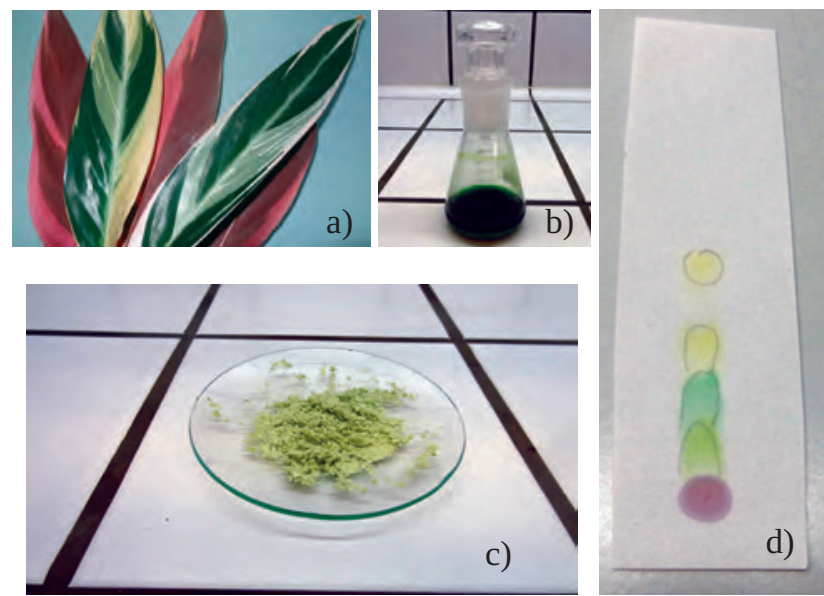

d)

Figura 3 - (a) Folhas de Stromanthe sanguinea 'Tricolor'; (b) Extrato bruto tratado com sulfato de sódio anidro; (c) Extrato sólido preparado por adsorção de (b) na superfície do amido da fécula de batata; (d) Cromatografia em papel obtida a partir do líquido (b). Adaptado com permissão de J. Chem. Educ. 92 (2015) 189-192. (Copyright 2015 American Chemical Society)

\section{Cromatografia em Coluna}

Uma seringa descartável de $20 \mathrm{~mL}$ foi empacotada com fécula de batata até preencher $3 / 4$ da sua capacidade e o extrato sólido foi aplicado na parte superior do empacotamento, imediatamente após a pré-eluição da coluna com éter de petróleo. Os solventes escolhidos para eluir os pigmentos foram éter de petróleo $40-60{ }^{\circ} \mathrm{C}$, misturas de éter de petróleo $40-60{ }^{\circ} \mathrm{C} /$ acetona (90:10 e 75:25), acetona e álcool etílico $[13,14]$. As frações foram isoladas de acordo com as variações visuais na cor das bandas separadas.

A eluição da coluna foi iniciada com éter de petróleo $40-60^{\circ} \mathrm{C}$ (Figura 4a) e depois da eluição de $\beta$-caroteno mudou-se para uma mistura de éter de petróleo $40-60{ }^{\circ} \mathrm{C}$ /acetona (90:10) (Figuras $4 \mathrm{~b}-4 \mathrm{c}$ ).

O eluente foi alterado novamente para uma mistura de éter de petróleo $40-60{ }^{\circ} \mathrm{C} /$ acetona (75:25) para eluir a clorofila $b$. Após eluição desta clorofila, passou-se acetona através da coluna para remover pigmentos minoritários (3-4 mL). O etanol (ou acetona adicional) foi usado para eluir os flavonóides. Esta última fração mostrou-se incolor e ficou vermelha por adição de solução aquosa de HCl 1M (Figura 4d).

A composição destas frações recolhidas foi avaliada por cromatografia em papel, usando uma mistura de éter de petróleo 40-60 ํㅡacetona (9:1) como fase móvel. Os resultados demonstraram que as frações continham os pigmentos previstos puros, com exceção da segunda fração amarela (xantofilas) que se encontrava ligeiramente contaminada com a clorofila $a$.

O tempo necessário para executar a atividade é uma aula prática de 2-3 h. Para classes de ensino básico com 90 min de duração, podem ser utilizadas duas sessões. $\mathrm{O}$ extrato pode ser preparado na primeira sessão, mas deve ser mantida a 8 ${ }^{\circ} \mathrm{C}$, protegido da humidade e da luz, e a sessão de separação em coluna deve ser realizada durante as $24-48 \mathrm{~h}$ seguintes.

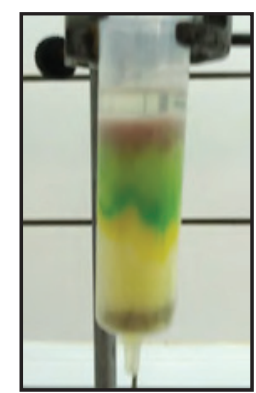

(a) $10 \mathrm{~min}$

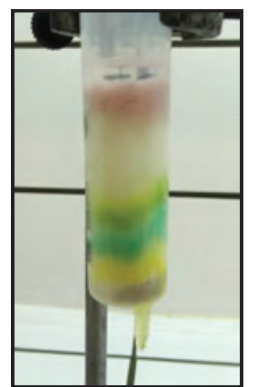

(b) 25 min

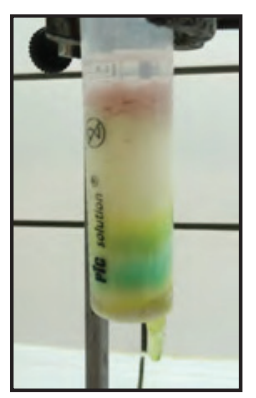

(c) $28 \mathrm{~min}$

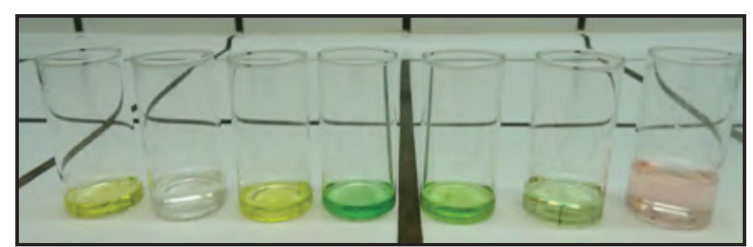

(d) $1 \mathrm{~h}$

Figura 4 - (a) Separação de $\beta$-caroteno e xantofilas numa coluna de fécula de batata por eluição com éter de petróleo; (b e c) Separação de xantofilas, clorofila $a$ e $b$ na mesma coluna por eluição com uma mistura de éter de petróleo/acetona 90:10; (d) Frações recolhidas a partir das folhas (3a). Adaptado com permissão de J. Chem. Educ. 92 (2015) 189-192. (Copyright 2015 American Chemical Society)

\section{Riscos e Medidas de Segurança}

A fécula de batata e o sal de cozinha são produtos comuns de uso doméstico, sem efeitos adversos para a saúde por inalação, ingestão e/ou contacto com a pele ou os olhos (em doses descritas). O éter de petróleo e a acetona são irritantes da pele e do pulmão. Estes solventes devem ser manipulados numa hotte, usando óculos e luvas de proteção. Eles também são líquidos inflamáveis, portanto não pode haver chamas no laboratório quando estas experiências estiverem a ser realizadas. O material de vidro deve ser manuseado com cuidado e devem ser usadas luvas e óculos de segurança pelos estudantes.

\section{Resultados e Discussão}

A separação cromatográfica dos pigmentos de folhas vermelhas e verdes, para além de melhorar o impacto visual da experiência equivalente realizada com folhas verdes, oferece potencialidades didáticas adicionais, uma vez que os componentes a separar são muito mais representativos em termos de diversidade de características físico-químicas. Em particular, os desafios de solubilidade enfrentados ao longo da experiência ajudarão o aluno a compreender os conceitos de solubilidade, forças intermoleculares e polaridade.

As estruturas químicas dos cinco pigmentos representados na Figura 1 devem ser fornecidas aos alunos e a aula deve ser iniciada com uma análise estrutural, identificando todos os grupos polares e apolares, no sentido de reconhecer as características de polaridade e solubilidade relativas. A acetona dever ser apresentada como um solvente adequado para a extração dos diferentes pigmentos pela sua polaridade intermédia, que a torna capaz de dissolver os pigmentos lipofílicos e hidrofílicos e ainda garantir a mis- 
cibilidade com a água presente nos tecidos vegetais. O seu baixo ponto de ebulição também é adequado para permitir a sua posterior eliminação. O extrato bruto líquido, obtido por maceração e filtração, é então submetido a uma análise por cromatografia em papel. A análise do cromatograma obtido (Figura 3d) permitirá relacionar a polaridade com a estrutura dos pigmentos e servirá para introduzir os princípios da cromatografia. Os alunos deverão então ser incentivados a prever o processo de eluição na cromatografia em coluna. Deverá ser enfatizada a importância de um aumento gradual da polaridade dos solventes a introduzir na coluna. A noção de série eluotrópica ajudará os estudantes a compreender a necessidade de eliminar a acetona e a água do extrato bruto. A capacidade de hidratação natural do sal de cozinha (ou sulfato de sódio anidro) foi utilizada para conseguir a eliminação da água residual (Figura 3b). A adsorção simples dos pigmentos na extensa superfície dos grãos do amido de batata permite a evaporação rápida da acetona à temperatura ambiente, levando a um extrato sólido (Figura 3d) adequado para aplicação na coluna. Assim, esta técnica evita a degradação dos pigmentos, a interferência de solventes polares na série eluotrópica, os desperdícios de solventes e meios sofisticados e/ou dispendiosos para preparação do extrato. Os conceitos de adsorção e hidratação podem ser discutidos com os alunos e podem ser suportados com vários exemplos escolhidos do dia a dia.

A análise visual da separação cromatográfica dos pigmentos na coluna permite estabelecer a correlação das estruturas moleculares (Figura 1) com as afinidades dos pigmentos para a fase móvel e estacionária (Figura 3). A eluição com éter de petróleo permitiu a separação de bandas amarelas, verdes e vermelhas na coluna (Figuras 3a e 4a). As antocianinas ficam retidas na parte superior da coluna, sendo facilmente identificadas pela coloração rosa. Esta forte adsorção ao amido revela o estabelecimento de ligações de hidrogénio fortes entre os grupos hidroxilo presentes no amido e nas antocianinas. Os carotenóides e as clorofilas, pigmentos lipofílicos, foram deslocados com velocidades diferentes pelo éter de petróleo. Os amarelos dos carotenóides, sendo menos polares, deslocam-se mais rapidamente do que os verdes das clorofilas. A banda amarela mais deslocada foi atribuída ao $\beta$-caroteno, por ser apolar, e foi completamente eluída pelo éter de petróleo, enquanto as xantofilas ficaram retidas no amido (Figura 4a) devido à presença de grupos polares oxigenados.

Aumentando a polaridade do eluente para uma mistura de éter de petróleo/acetona (90:10) foi possível separar três bandas muito bem definidas, uma banda amarela (xantofilas), uma banda azul-verde (clorofila $a$ ) e uma banda amarelo-verde (clorofila $b$ ) (Figura 4b-4c). Esta mistura eluíu facilmente as xantofilas (Figura 4c) e clorofila $a$. Para eluir a clorofila $b$ foi necessário aumentar a polaridade do eluente para mistura de éter de petróleo/acetona (75:25). A eluição de antocianinas foi alcançada com acetona ou etanol.

Foram obtidas pequenas diferenças no conteúdo das frações recolhidas, quando foram usadas diferentes plantas Somanthre sanguinea (Figuras 4d, 5a e 5b).
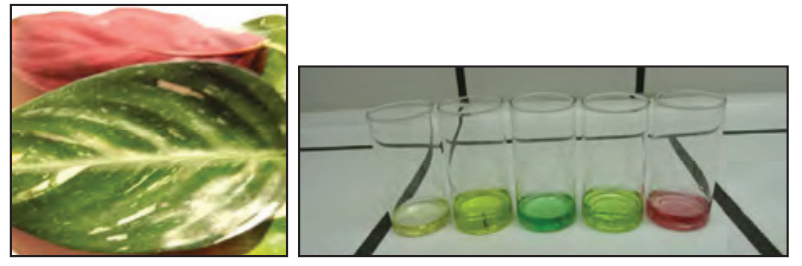

(a)
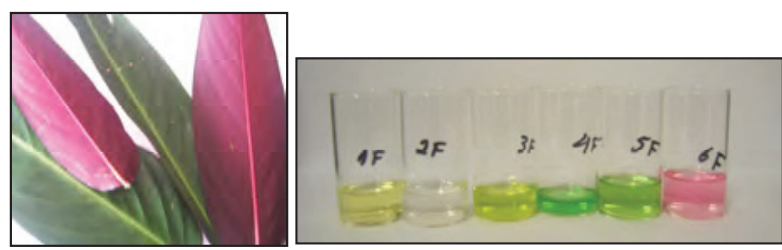

(b)

Figura 5 - (a-b) Principais frações recolhidas por separação numa coluna de fécula de batata de um extrato preparado a partir de folhas de plantas Somanthre sanguinea diferentes. Adaptado com permissão de J. Chem. Educ. 92 (2015) 189-192. (Copyright 2015 American Chemical Society)

Estes resultados demonstram que este método separa eficientemente os pigmentos das folhas verdes e vermelhas e permite analisar a composição dos pigmentos presentes em diversas folhas de plantas.

\section{CONCLUSÕES}

A utilização de fécula de batata como adsorvente na separação dos pigmentos presentes em folhas verdes e vermelhas por cromatografia em coluna constitui uma abordagem inovadora. Esta coluna também pode ser usada para extratos de folhas verdes, otimizando os resultados obtidos com os adsorventes usuais, como a sílica e a alumina, que requerem colunas mais compridas e mais estreitas. Além disso, a fécula de batata é muito mais acessível, uma vez que pode ser adquirida em qualquer supermercado a custo muito reduzido e é um material não tóxico e biodegradável.

Uma outra inovação desta atividade é a substituição de um extrato líquido por um extrato sólido, obtido por adsorção dos componentes do extrato líquido em amido de batata. Para além da simplicidade técnica e sustentabilidade do procedimento, acrescenta a grande vantagem de não se perder nenhum dos componentes do extrato original, permitindo a análise integral de diferentes tipos de folhas. Esta potencialidade pode ser explorada para o estudo dos pigmentos presentes em folhas de plantas sob o ponto de vista químico ou biológico e a atividade ganha um interesse renovado como ferramenta didática transversal à química e à biologia.

A introdução dos flavonoides através da utilização de folhas verdes e vermelhas acrescenta uma grande mais valia a esta atividade, devido ao interesse biológico e propriedades químicas desta classe de pigmentos. Os componentes do extrato destas folhas constituem ferramentas didáticas extraordinárias para demonstração dos fundamentos da química e da cromatografia, porque representam uma série de moléculas de polaridade muito mais abrangente, que se estende desde moléculas puramente lipofílicas (carotenos) 
até às moléculas exclusivamente hidrofílicas (antocianinas), todas facilmente detetadas a olho nu pelas suas cores características. Para além disso, a inclusão da cor vermelha no tradicional painel de cores verdes e amarelas, obtido a partir de extratos de folhas verdes, dá um colorido muito interessante à atividade, aumentando fortemente o seu impacto visual.

\section{AgRADECIMENTOS}

Os autores agradecem ao Departamento de Química da Universidade do Minho o apoio fornecido através de instalações e materiais laboratoriais e o apoio financeiro através do Centro de Química (projetos FCOMP-01-0124-FEDER-037302 e PEst C/QUI/UI0686/2013, Fundação para a Ciência e Tecnologia).

\section{REFERÊNCIAS}

[1] K. Andreoli, F. Calascibetta, L. Campanella, G. Favero, F. Occhionero, J. Chem. Educ. 79 (2002) 976-979

[2] M. Séquin, J. Chem. Educ. 82 (2005) 1787-1790
[3] F. Delgado-Vargas, A.R. Jiménez, O. Paredes-López, Crit. Rev. Food Sci. Nut. 40 (2000) 173-289

[4] J. Alkema, S.L. Seager, J. Chem. Educ. 59 (1982) 183-186

[5] D.L. Pavia, G.M. Lampman, G.S. Kriz, R.G. Engel, "Introduction to Organic Laboratory Techniques: a small scale approach”, Saunders College Publishing, New York, 1998, 352-359

[6] P. Anastas, N. Eghbali, Chem. Soc. Rev. 39 (2010) 301-312

[7] A.M. Dias, M.L.S. Ferreira, J. Chem. Educ. 92 (2015) 189 192

[8] H. Strain, J. Sherma, J. Chem. Educ. 46 (1969) 476-483

[9] S. Diehl-Jones, J. Chem. Educ. 61 (1984) 454-456

[10] W. Mewaldt, D. Rodolph, M. Sady, J. Chem. Educ. 62 (1985) 530-531

[11] N. Lalitha, J. Chem. Educ. 71 (1994) 432

[12] G. Horowitz, J. Chem. Educ. 77 (2000) 263-264

[13] A. Johnston, J. Scaggs, C. Mallory, A. Haskett, D. Warner, E. Brown, K. Hammond, M. McCormick, O. McDougal, J. Chem. Educ. 90 (2013) 796-798

[14] D. Kimbrough, J. Chem. Educ. 69 (1992) 987-988

\section{Actualidades CIentíicas}

\section{BIOPLÁSTICOS COM PROTEÍNAS}

A utilização de plásticos tradicionais à base de petróleo em muitas aplicações pode constituir um risco, podendo causar a infecção quando usados em aplicações médicas, e contaminação quando utilizados em embalagens de alimentos. Materiais não-tradicionais, como proteínas estão a ser testados para utilização potencial na produção de bioplásticos para aplicações que requerem materiais não contaminados.

Os bioplásticos produzidos a partir de proteínas, como a albumina ou o soro de leite, têm demonstrado actividades antibacterianas significativas. Estes resultados podem eventualmente levar à sua utilização em plásticos usados em aplicações médicas, como na cicatrização de feridas, suturas, tubos de cateter e libertação de fármacos. Os materiais bioplásticos também podem ser utilizados para a embalagem de alimentos.

Jones et al. testaram três bioplásticos não tradicionais como alternativas aos plásticos tradicionais, contendo albumina, proteínas de soro do leite e da soja para além de três plastificantes: água, glicerol, e látex de borracha natural.

Quando compararam as propriedades térmicas dos bioplásticos produzidos verificaram que as taxas de degradação eram semelhantes, com os bioplásticos de soja e de soro de leite a degradarem-se a temperaturas, entre 50 e $60{ }^{\circ} \mathrm{C}$, inferiores ao bioplástico com albumina. Em termos de propriedades viscoelásticas, os bioplásticos com albumina e com soro apresentaram propriedades semelhantes tendo em conta o plastificante utilizado, enquanto os plásticos com soja exibiram um maior intervalo de propriedades dependentes do plastificante. Quanto a propriedades antibacterianas, verificaram que plastificando tanto a albumina como o soro de leite com glicerol, se produziu o bioplástico com a maior actividade antibacteriana.

A utilização de bioplásticos permite também reduzir a quantidade de petróleo usado na produção de plástico tradicional para além de os bioplásticos serem totalmente biodegradáveis num aterro sanitário no prazo máximo de dois meses.

(adaptado de A. Jones, A. Mandal, S. Sharma, “Protein-based bioplastics and their antibacterial potential”, Journal of Applied Polymer Science, 2015; 132 (18) DOI: 10.1002/APP.419314)

António Mendonça

(mendonca@ubi.pt)

\section{EuCheMS 0 European Chemical Sciences}

